DOI 10.15593/2224-9354/2018.2.6

УДК 316.61:378.091.212.5

И.П. Миронов, Т.А. Белозерова

ЛИЧНОСТЬ СТУДЕНТА

В ПРОФЕССИОНАЛЬНОЙ ОРИЕНТАЦИИ ПЕРВОКУРСНИКОВ ПЕРМСКОГО ПОЛИТЕХНИЧЕСКОГО УНИВЕРСИТЕТА

\begin{abstract}
Рассмотрены вопросы оперативной помощи в оперативном самоопределении студентов на начальном этапе обучения в вузе. В статье показана динамика личностных изменений и позитивные процессы, которые происходят с первокурсниками политехнического университета в результате профессиональной ориентации студентов. Работа проводится совместно с психологической службой Управления социальной и внеучебной работы вуза. Пилотный профессионально ориентационный проект проводится второй год подряд, поэтому представленный в статье материал важен для целостного понимания профориентационной работы, выявления «плюсов» и «минусов», динамики процесса. Статистический материал наглядно подчеркивает успешность проекта в целом и очередного его этапа. Масштабность работы подтверждается объемом представленной выборки и несколькими надежными, валидными психодиагностическими методиками. Включение в проект обратной связи и осмысления результатов психодиагностики первокурсниками повышают достоверность полученных выводов. По мнению авторов, материал поможет в распространении позитивного опыта в других вузах, так как содержит ряд выводов, представляющих практический интерес для преподавателей высших учебных заведений, для средних учебных заведений различного профиля. Представленные выводы помогают работать и анализировать мотивацию. На примере мотивации обучения, особенностей адаптации личности первокурсников к обучению и сравнению с общеуниверситетскими данными мотивации и адаптации авторы показывают динамику личностных изменений. Подчеркнута важная роль кураторов академических групп в личностном и профессиональном развитии каждого студента факультета и некоторые аспекты, влияющие на успешность адаптации первокурсников.

Ключевые слова: профрессиональная ориентация, личностный рост, внеучебная работа, учебная мотивация, личностные ресурсы, образовательная среда, работа кураторов, психологическая диагностика, овладение профессией, адаптация к учебе.
\end{abstract}

Проблема профессионального самоопределения и ориентации связана с тем, что большое количество студентов приходят в вуз, обучаются, заканчивают его, получают профессию, однако не трудятся по полученной специальности. Согласно статистическим данным, около 60 \% выпускников в России не работают по профессии. Государство непродуктивно тратит значительные ресурсы на обучение молодых людей. Профориентационная работа в вузе направлена на студентов-первокурсников как основных субъектов обра-

(С) Миронов И.П., Белозерова Т.А., 2018

Миронов Игорь Петрович - психолог, Управление социальной и внеучебной работы ФГБОУ ВО «Пермский национальный исследовательский политехнический университет», e-mail: ipmironov@yandex.ru.

Белозерова Татьяна Аркадьевна - доцент кафедры «Строительный инжиниринг и материаловедение», заместитель декана по внеучебной работе, ФГБОУ ВО «Пермский национальный исследовательский политехнический университет», e-mail: bta.perm@mail.ru. 
зовательного процесса. Принято считать, что в 17-18 лет, возрасте поступления в вуз, у преобладающего числа молодых людей, личность полностью сформировалась. Однако в силу объективных и субъективных причин, которые мы в этой статье не рассматриваем, личность абитуриентов и первокурсников остается достаточно «пластичной». Значительная часть молодых людей находится в процессе профессионального самоопределения. Установки, ценности личности и уровень достижений молодых людей еще неустойчивы в выборе профессиональной направленности.

Часто на выбор вуза, факультета и профиля обучения в жизни влияют так называемые «слабые» мотивы, т.е. молодые люди поступают за компанию с друзьями, по настоянию родителей или из-за престижа специальности. Особенности контингента абитуриентов в настоящее время и требования по максимальному сохранению контингента студентов предъявляют необходимость оперативной помощи в профессиональном самоопределении молодых людей на начальном этапе обучения в вузе. В силу объективной «пластичности» личности молодых людей, на начальном этапе обучения имеется возможность проводить работу, повышающую мотивацию к обучению, раскрыть способности каждого индивидуума, для осмысленного выбора дальнейшего профиля обучения.

Проблема профессиональной ориентации абитуриентов и студентов имеет длительную историю. Эта проблема сопровождает высшее образование не только современной России, но и Советского Союза, несмотря на систему распределения. Система распределения «молодых специалистов» была введена в СССР именно потому, что необходимо было заполнить профессиональные вакансии без учета осознанного выбора своего профессионального маршрута, по принципу «надо для страны». В настоящее время в обществе дискутируется вопрос о целесообразности возврата к системе распределения выпускников. Однако, на наш взгляд, правильная организованная система профессиональной ориентации в вузе способна повысить осознанность своего профессионального выбора.

Авторы проекта предполагают, что профориентационной работой студентов на протяжении всего образовательного процесса можно способствовать развитию профессиональной мотивации, осознанности своего выбора дальнейшего обучения на факультете.

Цель, которую ставят авторы профориентационной работы на этом этапе, заключается в диагностике студентов «младших курсов» (первого и второго), формулировании психологической характеристики на каждого студента и получении обратной связи с осмыслением результатов, подтверждающих правильность своего выбора или изменения направления дальнейшего обучения.

На этапе обучения в вузе мотивация будущей профессиональной деятельности органично формируется в недрах учебной мотивации. Под профес- 
сиональными мотивами будем понимать такие мотивы, которые подвигают субъекта к совершенствованию собственной деятельности - ее способов, средств, форм и методов.

А.В. Сотникова говорит о том, что профессиональную мотивацию можно определить как совокупность потребностей, интересов, которые побуждают человека к профессиональной деятельности, к профессиональной самореализации и профессиональному совершенствованию [1].

Личность молодого человека на этом этапе активно изменяется, человек взрослеет. От профориентационной работы с первокурсниками зависит, какие мотивы в поведении и обучении будут развиваться, а какие нивелироваться, какие внутренние ресурсы нам удастся раскрыть. Очевидно, что на этапе овладения профессией, в учебном процессе мотивация, связанная с интересом к данной профессии, выступает в качестве ресурса и предпосылки, которые необходимы для развития профессионализма. Иными словами, в этот период студенту-первокурснику необходимы устойчивые профессиональные мотивы учебной деятельности и, очевидно, вполне адекватные представления о своей будущей работе. При наличии этих составляющих мотивации у студентов последние будут стремиться к постоянному развитию креативности, нацеленной на получение нового знания и формирования профессионально важных компетенций [1]. В противном случае значительное число студентов могут испытать разочарование, учиться формально и после окончания быть «потерянными» для профессии, на которую учились несколько лет [2]. Психическая напряженность, тревожность, беспокойство, неуверенность в будущем станут затруднять поиск себя в мире труда [3].

Исследования, проведенные психологической службой вуза, демонстрируют то, что преподавателям удается сохранить и на протяжении первого года обучения поддержать достаточно высокий уровень учебной мотивации.

Исследование проводилось на одном из факультетов политехнического университета в течение учебного года, в нем приняли участие 198 студентов первого курса восьми академических групп, 24-25 человек в каждой. Из них 85 юношей и 115 девушек. Весь поток обучается по единой для всех программе. Средний возраст - 18 лет.

Тестирование было проведено по двум методикам:

1) оценка мотивации обучения в вузе по методике Т.Н. Ильиной [4].

2) изучение уровня тревожности по методике Спилбергера [5].

В методике Ильиной имеются три оценочные шкалы: «приобретение знаний» (стремление к приобретению знаний, любознательность); «овладение профессией» (стремление овладеть профессиональными знаниями и сформировать профессионально важные качества); «получение диплома» (стремление приобрести диплом при формальном усвоении знаний, стремление к поиску обходных путей при сдаче экзаменов и зачетов). В опросник, для маскировки, 
автор методики включила ряд фоновых утверждений, ответы на которые, однако, можно с успехом использовать в качестве социологического опроса [4]. Методика Спилбергера оценивает адаптацию к успешному обучению в вузе за счет контроля ситуативной и личностной тревожности. Полученные с помощью выбранного надежного психодиагностического инструмента данные являются наиболее объективными и доступными в психологической деятельности. Подробнее об обосновании выбора методик психодиагностического инструмента авторами рассказано в статье [6].

В анализе полученных данных раскрывается ряд важных аспектов:

- интерес к получению знаний;

- интерес к овладению профессией;

- показатель формального отношения к обучению (по методике Т.Н. Ильиной).

На рис. 1 представлены основные данные в отношении желания получать знания, «жажды» учебы, овладении профессиональными компетенциями, а также способов достижения цели получения диплома (ответственной учебой или неприемлемыми способами). Данные строительного факультета (СТФ), на котором проходила профориентационная работа, сравнивались с общеуниверситетскими. Средние данные по университету были получены в течение четырех лет мониторинга на выборке из более 500 человек девяти факультетов. Сравнение демонстрирует, что первокурсники строительного факультета на $6,1 \%$ отстают в желании получать знания, учиться. Студенты на 1,3 \% в меньшей степени мотивированы на получение профессиональных компетенций. Но желание получить диплом, подтвержденный полноценными знаниями выше на 2,3 \% по отношению к вузовскому показателю. Ежегодный мониторинг мотивации обучения в вузе первокурсников строительного факультета дает возможность оперативно оценивать ситуацию с учебным процессом, корректировать учебно-воспитательный процесс с учетом того, что студенты менее активны в учебе, «жажде» получения знаний, несколько отстают от желания овладевать профессиональными знаниями и компетенциями.

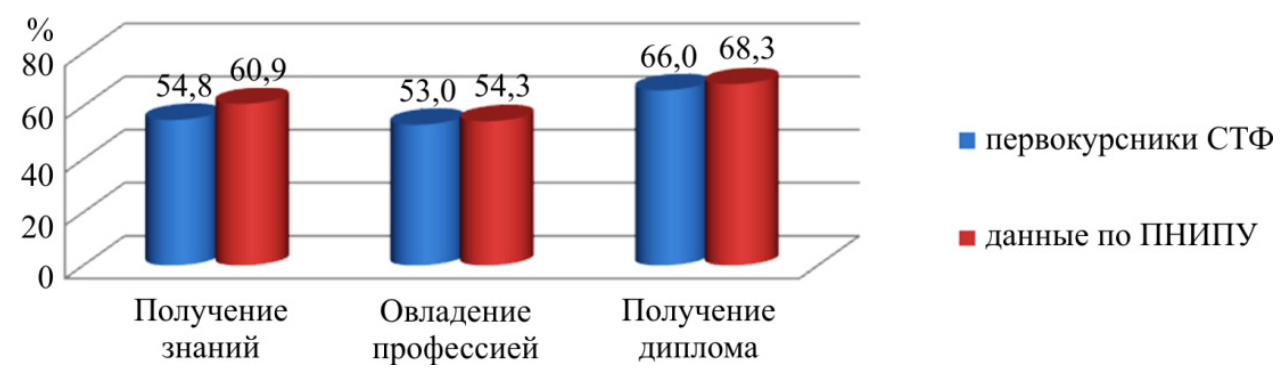

Рис. 1. Мотивация обучения в профессиональной ориентации первокурсников СТФ по сравнению с другими факультетами вуза 
Полученные данные диктуют необходимость сосредоточиться на работе с личностью тех студентов, которые еще недостаточно мотивированы на учебно-образовательную деятельность, используя образовательные и воспитательные функции. Существующее положение дел на факультете в настоящее время следует расценивать как ближайшую зону развития, направление совершенствования учебно-методической работы на строительном факультете. Можно оценить, какое количество внутренних ресурсов личности для повышения мотивации к обучению и профессиональному самоопределению. Далеко не полный перечень внутренних ресурсов, на которые направлена профориентационная работа, представлены ниже [7]:

- активная мотивация преодоления учебного стресса;

- отношение к своим победам и поражениям;

- уверенность в себе;

- позитивное и рациональное мышление;

- эмоционально-волевые качества; эмоциональный интеллект;

- знания;

- опыт преодоления подобных ситуаций;

- способность обратиться за помощью и принять помощь;

- умение формировать сеть поддержки;

- навыки психической саморегуляции;

- информационная активность;

- психологическая компетентность;

- тайм-менеджмент;

- поведенческие копинг-стратегии;

- поиск социальной поддержки;

- состояние здоровья; забота о сохранении и укреплении здоровья; наличие/отсутствие вредных привычек;

- наличие времени для отдыха;

- питание, сон.

Следует подчеркнуть, что изначально высокий интерес к освоению профессии, с которым абитуриенты приходят в вуз, дает студентам преимущество в дальнейшей учебе, является хорошей предпосылкой к освоению необходимых специалисту компетенций. Таких студентов более 50 \% от всего контингента, поступивших на первый курс (см. рис. 1).

Руководство факультета стремится к поиску новых форм и методов развития личности студентов оставшейся половины, не боится экспериментировать, стремясь сохранить весь контингент поступивших. В результате закономерно формируется хорошо организованная образовательная среда, ответственное отношение преподавателей к своим обязанностям в отношении 
студентов. В частности выявляются причины низкой успеваемости в период учебных аттестаций и предлагаются пути повышения успешности освоения учебных программ.

Тестирование и анкетирование деловых и личностных качеств показало, что из 195 первокурсников факультета 37 \% в конце первого года обучения устойчиво мотивированы на получение профессиональных знаний и в полной мере интересуются содержательной стороной учебного процесса, предметами учебных программ (рис. 2). Из важнейших личностных качеств, помогающих в освоении учебных программ, студенты-первокурсники на первые позиции ставят такие, как ответственность, трудолюбие и усидчивость в учебной деятельности.

Преподавателям и кураторам академических групп в обучении следует более полно и эффективно использовать эти «сильные» стороны личности студентов.

На рис. 3 можно увидеть, насколько трудно студентам было учиться на первом курсе.

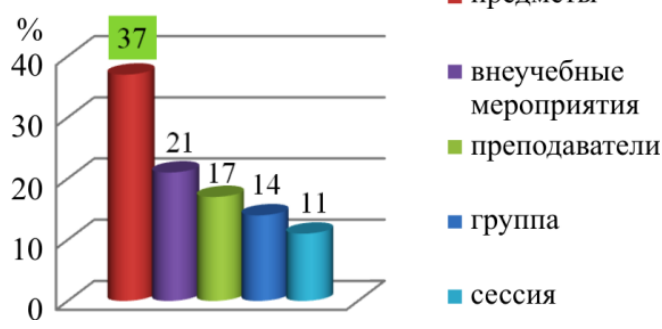

Рис. 2. Распределение ответов на вопрос, что больше всего запомнилось за первый год учебы

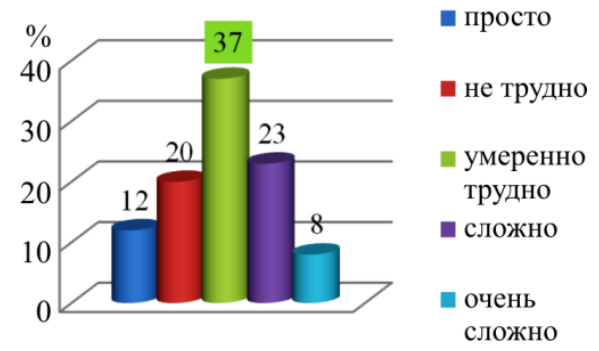

Рис. 3. Распределение ответов на вопрос, насколько трудно было учиться на первом курсе

Можно предположить стремление к обучению по выбранной профессии у 37 \% студентов, которые ставят учебные предметы на первое место в рейтинге самого интересного и запомнившегося на первом курсе (см. рис. 2).

Без успешной и своевременной адаптации невозможна эффективная деятельность в учебном процессе. Выявлено то, что более половины обучающихся студентов строительного факультета в течение первого года успешно адаптируется к новой для себя учебной деятельности (рис. 4).

Следует подробнее остановиться на внеучебной работе кураторов факультета, важной в профессиональной работе первокурсников. Внеучебная работа кураторов академических групп способствует поддержанию высокой учебной мотивации на должном уровне на весь период обучения [8]. С каждым годом повышается роль, которую играют кураторы, назначенные в академические группы младших курсов. На некоторых факультетах сообщество студентов (академическая группа) рассматривается как формальная группа людей, в работе с которой кураторы составляют лишь наиболее об- 
щие, формальные планы, не работая или работая с группой, особо не вникая в особенности характера каждого из ее членов. Внеучебная работа на строительном факультете организована таким образом, что кураторы относятся к студентам академических групп максимально доброжелательно: как к сообществу в целом, т.е. коллективу, который способен сам позитивно влиять на каждого его члена, а также исходя из уникальности личности каждого студента в этом сообществе.

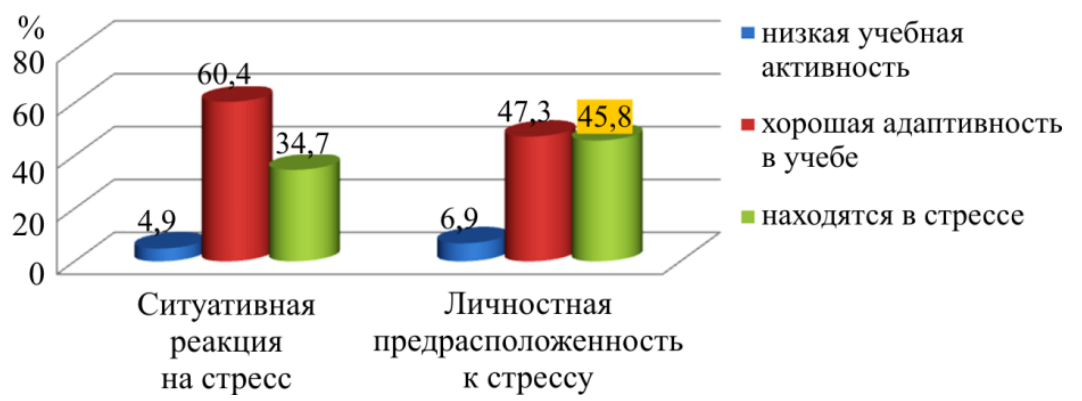

Рис. 4. Дифференциальная оценка состояния адаптации студентов первого курса строительного факультета

На протяжении всего периода обучения, особенно на первом курсе, на факультете проводится индивидуальная работа с каждым студентом, учитываются его психофизические особенности, умение адаптироваться в коллективе, лидерские качества. Каждый член группы является уникальной личностью, которая успешно развивается без подавления других, имеющих свои особенности характера, личные цели и устремления. Одновременно, находясь в коллективе, он подчиняется общим правилам сосуществования. Так, со временем появляется взаимовыручка, взаимопомощь, солидарность, эмоциональная поддержка и дружеские отношения, усиливается ответственность.

Чем больше ярких личностей проявляется в ходе этой работы, тем интересней и продуктивнее жизнь в таком коллективе, будь то группа, курс или факультет. Дружеская обстановка способствует более успешному освоению учебных программ, студенту легче сориентироваться в потоке учебной деятельности, разобраться в своих способностях и приоритетных ценностях. Необходимо формировать и поддерживать комфортную среду обучения.

Таким образом, оценивая представленную в статье динамику изменений личности, которая происходит у первокурсников в процессе целенаправленной профориентационной работы, следует отметить, что все усилия, прилагаемые авторами проекта, оправданы и позитивны.

Следовательно, необходимо продолжить проводить профессиональную ориентацию на факультете и дальнейшие исследования по предложенным методикам по нескольким причинам: 
1) это позволяет содействовать максимальному раскрытию способностей студентов и помощи в осмысленном и взвешенном выборе будущего профиля обучения в первый год;

2) результаты тестирования позволяют студенту глубже вникнуть в свои проблемы. Объективные данные характеристики заставляют задуматься и более взвешенно подойти к своим возможностям в обучении выбранной профессии;

3) это способствует диссеминации инновационного опыта на другие факультеты университета.

В заключение следует отметить, что полученные в результате исследовательской работы данные свидетельствуют о правильном выборе направления профориентационной работы, изложенной в гипотезе и прежде всего, осознанность студентами своего выбора направления дальнейшего обучения на факультете. Подобранные методики исследования и анализ полученных данных позволили решить поставленные задачи текущего учебного года. Большая часть студентов-первокурсников, принимающих участие в исследовании, приветствует выбранный авторами проекта личностно ориентированный подход к профориентации. Об этом свидетельствует высокая оценка обратной связи (рефлексии): 8 баллов из 10 (в выборке 195 человек). При этом студентам первого курса оставляют право своего выбора дальнейшего профиля обучения. Авторы профориентационного проекта лишь подводят молодых людей к более осознанному личностному выбору. Во многом эта работа способствует принятию судьбоносного решения о своем профессиональном маршруте. Если студенты на основе анализа своей личности решат, что выбор сделан верный и единственно правильный, то у молодого человека появится уверенность в своих силах, желание учиться дальше, раскрывая свои ресурсы. В том случае, если в течение первого года обучения проявились серьезные сомнения в правильности или произошло осознание случайности выбора профессии, то в течение первого или даже второго курса значительно проще изменить направление своего профессионального маршрута, чем сделать это в конце обучения, тем самым предостеречь от непродуктивной траты бюджетных средств.

Результаты проведенного исследования профориентационной работы строительного факультета и психологической службы ПНИПУ являются полезным опытом не только для факультетов вуза, но и для других заинтересованных в активной профессиональной работе вузов России.

\section{Список литературы}

1. Лаврентьева И.В., Игнатенко К.М. Выявление учебно-профессиональной мотивации в процессе обучения в вузе (на материале тестирования студентов-дефектологов 1-3 курсов) // Молодой ученый. - 2015. - № 6. С. $778-783$. 
2. Климов Е.А. Психология профессионального самоопределения: учеб. пособие. - М.: Academia, 2004. - 301 с.

3. Зеер Э.Ф. Психология профессий: учеб. пособие. - М.: Академический Проект, 2003. - 336 с.

4. Мотивация персонала: учеб. пособие / Ю.Г. Одегов, Г.Г. Руденко, С.Н. Апенько, А.И. Мерко. - М.: Альфа-Пресс, 2010. - 640 с.

5. Энциклопедия психодиагностики. Шкала тревоги Спилбергера [Электронный ресурc]. - URL: http://psylab.info/ (дата обращения: 09.10.2017).

6. Миронов И.П., Белозерова Т.А. Психологическая диагностика - основа профессиональной ориентации студентов-первокурсников строительного факультета // Формирование гуманитарной среды в вузе: Инновационные образовательные технологии. Компетентностный подход: сб. материалов 16-й Всерос. науч.-практ. конф. - Т. 2. - Пермь, 2016. - С. 171-179.

7. Мухаметзянов И.Ш. Негосударственный вуз как субъект образовательной деятельности: реалии и перспективы. - Казань: Академия социального образования, 2013. $-270 \mathrm{c}$.

8. Профориентационные игры: практикум по профориентационной работе / 3.В. Горбачева, О.Н. Кащеева [и др.]; под ред. И.В. Кузнецовой. - Ярославль: Ресурс, 2004. - 120 с.

\section{References}

1. Lavrent'eva I.V., Ignatenko K.M. Vyiavlenie uchebno-professional'noi motivatsii $\mathrm{v}$ protsesse obucheniia $\mathrm{v}$ vuze (na materiale testirovaniia studentovdefektologov 1-3 kursov) [Identification of educational and professional motivation in the learning process at University (based on testing results gained from 1-3 years students in defectology)]. Molodoi uchenyi, Kazan', 2015, no. 6, pp. 778-783.

2. Klimov E.A. Psikhologiia professional'nogo samoopredeleniia [Psychology of professional self-determination], Moscow, Academia, 2004, 301 p.

3. Zeer E.F. Psikhologiia professii [Psychology of professions]. Moscow, Akademicheskii Proekt, 2003, 336 p.

4. Odegov Iu.G., Rudenko G.G., Apen'ko S.N., Merko A.I. Motivatsiia personala [Motivation of staff]. Moscow, Al'fa-Press, 2010, 640 p.

5. Entsiklopediia psikhodiagnostiki. Shkala trevogi Spilbergera [Encyclopedia of psychodiagnostics. The Spielberg scale of anxiety], available at: http://psylab.info/ (accessed 9 October 2017).

6. Mironov I.P., Belozerova T.A. Psikhologicheskaia diagnostika - osnova professional'noi orientatsii studentov pervokursnikov stroitel'nogo fakul'teta [Psychological diagnosis as the basis of professional orientation of construction faculty freshmen students]. Innovatsionnye obrazovatel'nye tekhnologii. Kompetentnostnyi podkhod: materialy 16 Vserossiiskoi nauchno-prakticheskoi konferentsii. Vol. 2. Perm, 2016, pp. 171-179. 
7. Mukhametzianov I.Sh. Negosudarstvennyi vuz kak sub"ekt obrazovatel'noi deiatel'nosti: realii i perspektivy [Non-state institution of higher education as a subject of educational activities: realities and prospects]. Kazan, Academy of Social Education, 2013, pp. 270.

8. Gorbacheva Z.V., Kashheeva O.N. et al. Proforientatsionnye igry: praktikum po proforientatsionnoi rabote [Career-oriented games: a workshop on vocational guidance]. Ed. I.V. Kuznetsova, Yaroslavl, Resurs, 2004, 120 p.

Оригинальность $89 \%$

Получено 26.09.2017 Принято 30.10.2017 Опубликовано 29.06.2018

I.P. Mironov, T.A. Belozerova

\title{
THE STUDENT IDENTITY IN THE PROFESSIONAL ORIENTATION OF FIRST-YEAR STUDENTS IN PERM POLYTECHNIC UNIVERSITY
}

\begin{abstract}
The article presented by the authors seems to be relevant as it solves questions of operational assistance for students' self-determination at the initial stage of university studies. The article deals with dynamics of personality changes and positive processes that occur with Polytechnic University freshmen as a result of students' professional orientation. These studies are being carried out jointly with Psychological Service of Social and Extracurricular Work Department. A pilot vocational project is being implemented for the second consequent year, for which reason the material presented in the article is important for holistic understanding of career-oriented work, identifying "pros" and "cons", along with the process dynamics. Thes statistical material clearly underlines the success of the project as a whole and its next stage. The large scope of work is confirmed by the volume of sampling provided and certain reliable psychodiagnostic techniques. The feedback included and reflection of psychodiagnostic results gained by freshmen increase reliability of conclusions. According to the authors, the material will help to disseminate positive experiences at other universities because it contains a number of conclusions of practical interest for university teachers, as well as for vocational college teachers in various fields. Conclusions that have been made can help to work and analyze motivation. The dynamics of personality changes based on learning motivation, personal peculiarities of freshmen adaptation to learning in comparison to the common university data are shown. The importance of academic group tutors in personal and professional development of each student and some aspects influencing the successful adaptation of freshmen are highlighted.

Keywords: professional orientation, personal growth, extracurricular activities, learning motivation, personal resources, educational environment, work of tutors, psycho-diagnostics, profession mastering, adaptation to studies.
\end{abstract}

Igor P. Mironov - Psychologist, Bureau of Social and Extracurricular Work, Perm National Research Polytechnic University, e-mail: ipmironov@yandex.ru.

Tatyana A. Belozerova - Associate Professor, Construction Engineering and Materials Science Department, Deputy Dean for Extracurricular work, Perm National Research Polytechnic University, e-mail: bta.perm@mail.ru.

$$
\text { Received 26.09.2017 Accepted 30.10.2017 Published 29.06.2018 }
$$

